\title{
Çörtlerin betonun alkali silika reaksiyonu üzerindeki etkisi
}

\author{
The effect of cherts on alkali silica reaction of concrete
}

\author{
Hasan EKER*1,a, Demet DEMIR ŞAHİN ${ }^{2, b}$ \\ ${ }^{1}$ Gümüşhane Üniversitesi, Mühendislik ve Doğa Bilimleri Fakültesi, Maden Mühendisliği Bölümü, 29100, Gümüşhane \\ ${ }^{2}$ Gümüşhane Üniversitesi, Gümüşhane Meslek Yüksekokulu, Madencilik ve Maden Çıkarma Bölümü, 29100, Gümüşhane
}

• Geliş tarihi / Received: 18.02.2021 • • • Düzeltilerek geliş tarihi / Received in revised form: 01.04.2021 • Kabul tarihi / Accepted: 14.04 .2021

\begin{abstract}
$\ddot{O} z$
Betonun durabilitesini etkileyen kimyasal reaksiyonlardan biri de alkali silika reaksiyonudur (ASR). Gümüşhane ilinde yer alan taş ocaklarının birçoğunda bol miktarda çörtler yer almaktadır. Bu çörtler delme patlatma yöntemiyle ana kayaçtan ayrılarak elde edilen ince ve kaba agregalarla birlikte beton bileşeni olarak kullanılmaktadır. Bu çalışmada; Gümüşhane ilinin 3 farklı bölgesinden alınan çörtler (Akçakale, Gümüşhane ve Besyo), Gümüşhane üniversitesinde yer alan beton laboratuvarına getirilmiştir. Daha sonra farklı bölgelerden alınan 3 farklı çört ve referans numunesi için beton karışım hesabı yapılmış ve bu karışım hesaplarına göre ASTM C 1260 hızlandırılmış harç çubuğu standardına göre beton örnekleri hazırlanmıştır. 3, 7, 14 ve 28 günlük kür süreleri için 3 adet hızlandırılmış harç çubuğu numunesi hazırlanmıştır. Her bir bölgenin çört karışımlarına ait harç numunelerinin 3, 7, 14 ve 28 gün sonundaki ASR ölçümleri gerçekleştirilmiştir. Sonuçlar; çört ile üretilen tüm numunelerin, referans numunesine göre daha yüksek boy değişimi değerine sahip olduğunu, kür süresine bağlı olarak boy değişim değerlerinin arttığını göstermiştir. 14 günlük boy uzama sonuçlarının ASTM C 1260'ta belirtilen \% 0.1 zararsız agregalar için boy uzama limitini ve 28 günlük boy uzama sonuçlarının da \% 0.2'den fazla boy uzaması değerlerini aştığı görülmüştür. Sonuç olarak; Akçakale, Gümüşhane ve Besyo çörtlerinin 14 ve 28 günlük kür süreleri göz önüne alındığında ASR açısından zararlı olduğu anlaşılmıştır.
\end{abstract}

Anahtar kelimeler: Agrega, Alkali silika reaksiyonu (ASR), Beton, Çört, Gümüşhane

\begin{abstract}
One of the most important chemical reactions affecting the durability of concrete is the alkali silica reaction (ASR). There are plenty of cherts in many of the quarries in Gümüshane province. These cherts are used as concrete component together with fine and coarse aggregates obtained by separating from the bedrock by drilling and blasting method. In this study; The cherts (Akçakale, Gümüşhane ve Besyo) taken from 3 different regions of our province of Gümüşhane were brought to the concrete laboratory in our Gümüshane University. Later, 3 different cherts and reference concrete mixtures taken from different regions were prepared and concrete samples were prepared according to ASTM C 1260 accelerated mortar bar standard. ASR measurements of the mortar samples belonging to the chert mixtures of each region at the end of 3, 7, 14 and 28 days were performed. The results are; it has shown that all samples produced with cherts have a higher length change value than the reference sample, and the length change values increase depending on the curing period. It is observed that 14-day lengthening results exceed the lengthening limit for $0.1 \%$ hazardous aggregates specified in ASTM C 1260 and 28-day lengthening results exceeding the lengthening values of more than $0.2 \%$. As a result; It was understood that Akçakale, Gümüşhane and Besyo cherts were harmful to ASR considering the curing times of 14 and 28 days.
\end{abstract}

Keywords: Aggregate, Alkali silica reaction (ASR), Concrete, Chert, Gümüşhane

\footnotetext{
${ }^{{ }^{*} a}$ Hasan EKER; eker_hasan78@ @otmail.com, Tel: (0544)7397903, orcid.org/0000-0003-2644-4681

${ }^{\mathrm{b}}$ orcid.org/0000-0003-0338-65621
} 


\section{Giriş}

Beton; agrega (ince ve kaba agrega), çimento, suyun, kimyasal ve mineral katkı maddelerin ilave edilerek veya edilmeden homojen olarak karıştırılması sonucu elde edilen, başlangıçta plastik kıvamda olan ve zamanla katılaşıp sertleşen yap1 malzemesi olarak ifade edilmektedir (Baradan, 2004). Betonda bazı reaksiyonlar meydana gelmektedir. Bu reaksiyonlardan biri de alkali silika reaksiyonudur.

Alkali-silika reaksiyonu 1940'lı y1llarda Stanton (1940) tarafindan ortaya konulmuştur. Alkali silika reaksiyonu (ASR), betonun durabilitesini etkileyen en önemli kimyasal reaksiyonlardan biridir (Karakurt ve Topçu, 2011; Demir ve Arslan, 2013; Gökçe vd., 2013; Yurtdas vd., 2013; Adıgüzel vd. 2019; Gökçe vd., 2019). Bu ASR reaksiyonu; betonun bünyesinde bulunan nem ile birlikte genişleyen bir jelin oluşmasını sağlayarak yeterli derecede ve miktarda alkali etkisinin oluşmasına neden olur. Bu jel hacim artışına ve şişmeye sebep olduğundan betonda çatlakların oluşmasına neden olan çekme gerilmelerini oluşturmaktadır (Demir, 2010; Demir ve Arslan, 2013; Çelik ve Şahbaz, 2017).

ASR hasarı, Eşitlik 1'de verilen bir dizi ardışık reaksiyonun sonucudur: bu reaksiyon; yarı kararlı silikanın çözünmesi (1), nano-koloidal silika çözeltisinin oluşumu (2), çözeltinin jelleşmesi (3) ve jelin şişmesi (4) (Rajabipour vd., 2015) şeklinde meydana gelir. $\mathrm{Bu}$ reaksiyonlar arasında, silika çözünmesi genellikle en yavaş olanıdır (Brantley vd., 2008) ve bu nedenle, öncelikle betondaki ASR oranı kontrol edilmelidir.

$\mathrm{SiO}_{2 \text { katı }} \stackrel{1}{\longrightarrow} \mathrm{SiO}_{2 \text { sulu }} \stackrel{2}{\longrightarrow} \mathrm{SiO}_{2}$ ç̈zzelti $\stackrel{3}{\longrightarrow} \mathrm{SiO}_{2 \text { jel }} \stackrel{4}{\longrightarrow}$ Genleşme

Betonda ASR; genleşme, çatlama, yüzeysel tortu oluşumuna, parça atmasına ve yer değiştirmelere sebep olmaktadır. Bu durumların oluşumu betonda istenmemektedir. ASR oluşumu; kullanılan agreganın özelliklerine, betonun alkali içeriğine, betonun geçirimliliğine, nem durumuna, ortam sıcaklığına gibi faktörlere bağlıdır (Rajabipour vd., 2015). ASR'nin gerçekleşmesi; reaktif agregalar, yüksek su içeriği ve yüksek konsantrasyon sahip alkali varlığının aynı anda ortamda olması ile oluşmaktadır (Charpin ve Ehrlacher, 2012).

ASR çeşitli faktörlere bağlıdır. Bu faktörler; agrega özellikleri, betonun alkali içeriği, betonun geçirimliliği, nem durumu, ortam sıcaklığı, diş alkaliler, buz çözücü tuzlar, deneysel koşullar, reaktif silika içeriğidir (Lindgard vd., 2012; Gao vd., 2013). Agrega içeriğin de bulunan çörtte, ASR'unu etkileyen faktörlerden biridir.

Çört, bir grup olarak, silisli kayaçlar için kullanılan genel bir terimdir. Bir çört, kimyasal olarak çöktürülmüş bir tortul kaya olup, esasen monomineraliktir ve başlıca mikrokristalin, kalsedonik kuvars ile birlikte alt megakuvarsdan oluşmaktadır (Folk, 1980). Çörtler, \% 95 veya daha fazla silika içerebilir. Kimyasal olarak etkisiz, yıpranmaya ve değişime karşı oldukça dirençli, jeokimyasal çalışmalar için uygundur (Eker vd., 2012). Bu kayaçlar Prekambriyenden Tersiyere kadar değişik yaşlardaki dizilerde yaygın olarak bulunmalarına karşın, tüm tortul kayaçların yaklaşık \% 1'den daha az bir kısmını oluşturmaktadırlar. Çoğunlukla mikrokristalen kuvarstan meydana gelmektedirler. Buna çok az miktarlarda kalsedon ve olasılıkla opal de eşlik etmektedir. Opal duraysız olup, zamanla kuvarsa dönüşür (Çörtler, 2020).

Betonda kullanılan agregaların bünyesinde bulunan çörtün alkali reaktif olabileceği belirtilmektedir. Japonya, ABD ve İngiltere'de yapılan bazı çalışmalarda çört içeren betonların alkali silika reaksiyonuna neden olduğu belirtilmektedir (Gogte, 1973; Williams vd., 1982; Nishiyama vd., 1989; Jones, 1989; Morino, 1989; Swamy, 1992; Strogen, 1993; Wakizaka, 2000; Larbi ve Visser, 2002; Bektas vd., 2004, 2008; McNally vd., 2004; Richardson, 2005; Iwatsuki ve Morino, 2008).

Gümüşhane ilinde yer alan taş ocaklarının birçoğunda agrega malzemesi olarak bol miktarda çörtler yer almaktadır. Bu çörtler delme patlatma yöntemiyle ana kayaçtan ayrılarak elde edilen ince ve iri agregalarla birlikte beton bileşeni olarak kullanılmaktadır. Bu çalışmada; Gümüşhane ilinin 3 farklı bölgesinden alınan çörtlerin, betonda agrega bileşeni olarak kullanılması ile hazırlanan harçlarının alkali silika reaksiyonu (ASR) üzerindeki etkisi araştırılmıştır. Böylece; Gümüşhane bölgesinde çört içeren ocaklardan alınan agregaların, beton üzerine etkisinin belirlenmesi amaçlanmıştır. 


\section{Materyal ve metot}

Deneysel çalışmalarda çimento, agrega, Akçakale (A), Gümüşhane $(\mathrm{G})$ ve Besyo (B) bölgelerinden elde edilen çörtler ve şebeke suyu kullanılmıştır.

\subsection{Kullanılan malzemelerin özellikleri}

Hazırlanan harç karışımlarında CEM I 42.5 R Portland çimentosu kullanılmış ve Gümüşhane
Aşkale çimento fabrikasından temin edilmiştir. Kullanılan çimentonun özgül ağırlığı $3.08 \mathrm{~g} / \mathrm{cm}^{3}$, özgül yüzey alanı $4145 \mathrm{~cm}^{2} / \mathrm{g}, 45 \mu$ elek üstü \% 8.58 'dir. Kimyasal analiz sonuçlarına göre; kızdırma kayb1 \% 7.19, serbest $\mathrm{CaO} \% 0.38, \mathrm{SiO}_{2}$ $\% 18.59, \mathrm{SO}_{3} \%$ 2.89'dir. Çimentonun kendine özgü fiziksel, kimyasal ve mekanik özellikleri Tablo 1'de verilmiştir.

Tablo 1. CEM I 42.5 R tipi çimentonun özellikleri

\begin{tabular}{|c|c|c|c|}
\hline \multicolumn{2}{|c|}{ Kimyasal Analizler (\%) } & \multicolumn{2}{|l|}{ Fiziksel Testler } \\
\hline $\mathrm{SiO}_{2}$ & 18.59 & İncelik (45 $\mu$ elek üstü \%) & 8.58 \\
\hline $\mathrm{Al}_{2} \mathrm{O}_{3}$ & 4.69 & Özgül Ağırlık ( $\left.\mathrm{gr} / \mathrm{cm}^{3}\right)$ & 3.08 \\
\hline $\mathrm{Fe}_{2} \mathrm{O}_{3}$ & 3.04 & Özgül Yüzey $\left(\mathrm{cm}^{2} / \mathrm{gr}\right)$ & 4145 \\
\hline $\mathrm{CaO}$ & 60.34 & Priz Başlangıcı (saat-dk) & $2 \mathrm{~s}-33 \mathrm{dk}$ \\
\hline $\mathrm{MgO}$ & 1.92 & Priz Sonu(saat-dk) & $3 \mathrm{~s}-18 \mathrm{dk}$ \\
\hline $\mathrm{SO}_{3}$ & 2.89 & Hacim Genişlemesi(mm) & 0.7 \\
\hline K1zdırma Kaybı & 7.19 & Su İhtiyacı \% & 29.9 \\
\hline $\mathrm{Na}_{2} \mathrm{O}$ & 0.11 & & \\
\hline $\mathrm{K}_{2} \mathrm{O}$ & 0.64 & & \\
\hline CI & 0.0189 & Basınç Dayanımı( $\left.\mathrm{N} / \mathrm{mm}^{2}\right)$ & \\
\hline Ölçülemeyen & 0.57 & 2.Gün & 23.9 \\
\hline Toplam & 100 & 28.Gün & 51.1 \\
\hline s. $\mathrm{CaO}$ & 0.38 & & \\
\hline Katk1\% & 17.87 & & \\
\hline
\end{tabular}

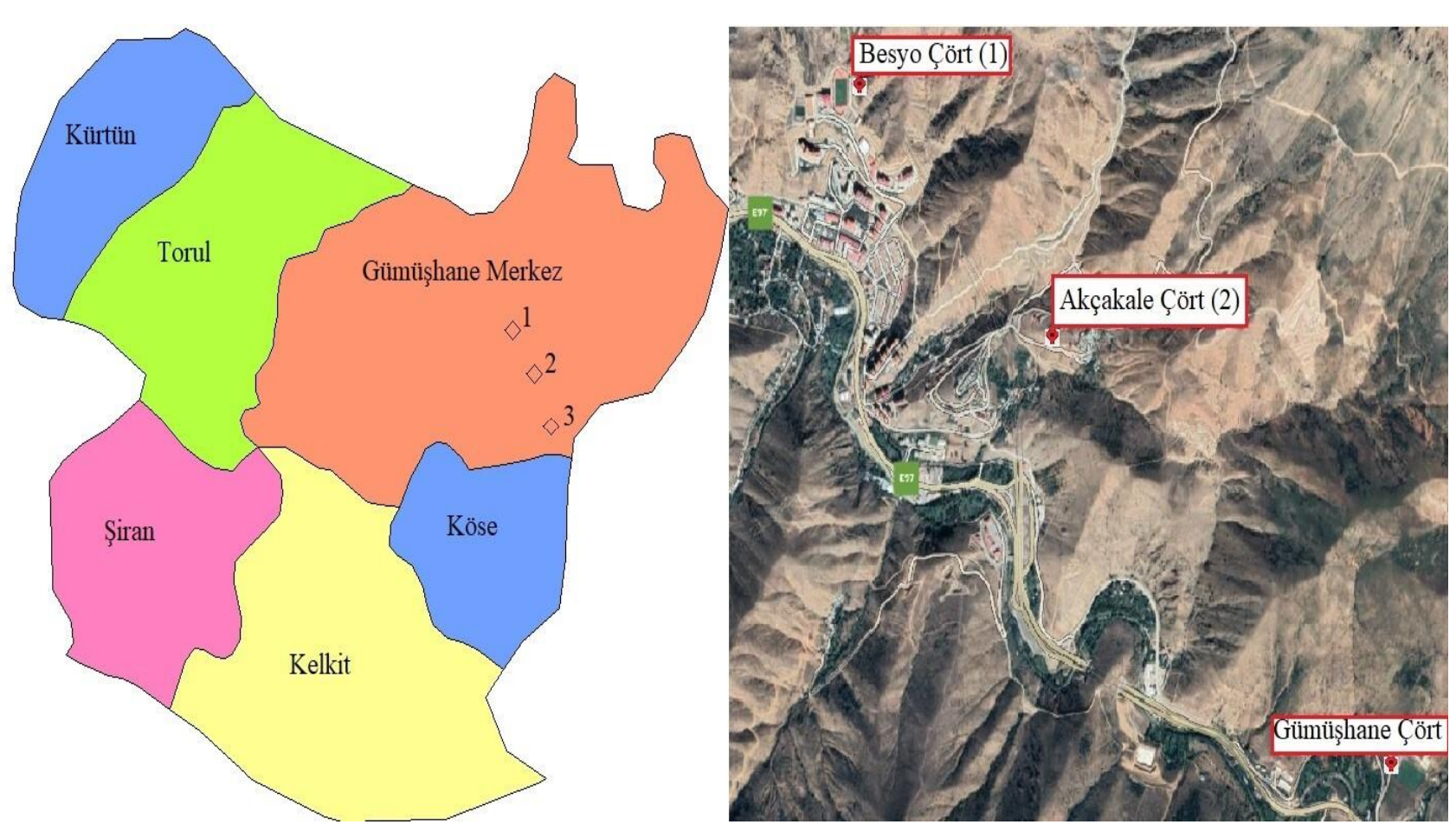

Şekil 1. Çalışmada kullanılan çörtlerin yer buldur haritası

Referans beton harçlarının bileşiminde kullanılan agregalar Gümüşhane yöresine ait kireçtaşlarından oluşmaktadır. Referans olarak tabir edilen kireçtaşı agregası; Gümüşhane ilindeki taş ocaklarında yer almas1 ve beton santrallerinde bu kayacin kullanılması nedeniyle tercih edilmiştir. Çalışmada kullanılan çörtler ise Gümüşhane ilinde yer alan Akçakale (A), Gümüşhane (G) ve Besyo (B) bölgelerinden tedarik edilmiştir (Şekil 1). Tablo 2'de G, B ve A bölgelerinden alınan çörtlerin kimyasal özellikleri verilmiştir. $\mathrm{G}, \mathrm{B}$ ve A bölgelerinin ve kireçtaşının (kullanılan agrega) 
sırasıyla özgül ağırlıkları $2.69 \mathrm{~g} / \mathrm{cm}^{3}, 2.64 \mathrm{~g} / \mathrm{cm}^{3}$, $2.67 \mathrm{~g} / \mathrm{cm}^{3}$ ve $2.77 \mathrm{~g} / \mathrm{cm}^{3}$ 'tür. Özgül yüzey alanları ise $1108 \mathrm{~cm}^{2} / \mathrm{g}, 1280 \mathrm{~cm}^{2} / \mathrm{g}, 889 \mathrm{~cm}^{2} / \mathrm{g}$ ve 952 $\mathrm{cm}^{2} / \mathrm{g}$ 'dir.
Tablo 2'de hızlandırılmış harç çubuğu deneyinde kullanılan agrega ve çörtlerin karışım miktarları verilmiştir. Ayrıca karışımlarda Gümüşhane ili şebeke suyu kullanılmıştır.

Tablo 2. Hızlandırılmış harç çubuğu deneyinde kullanılan agrega ve çörtlerin kimyasal özellikleri

\begin{tabular}{llllllllll}
\hline Çörtler & $\begin{array}{l}\text { Kuzdırma } \\
\text { Kaybı (\%) }\end{array}$ & $\begin{array}{l}\mathrm{SiO}_{2} \\
(\%)\end{array}$ & $\begin{array}{l}\mathrm{Al}_{2} \mathbf{O}_{3} \\
(\boldsymbol{\%})\end{array}$ & $\begin{array}{l}\mathrm{Fe}_{2} \mathbf{O}_{3} \\
(\boldsymbol{\%})\end{array}$ & $\begin{array}{l}\mathbf{C a O} \\
(\boldsymbol{\%})\end{array}$ & $\begin{array}{l}\mathrm{MgO} \\
(\%)\end{array}$ & $\begin{array}{l}\mathrm{SO}_{3} \\
(\boldsymbol{\%})\end{array}$ & $\begin{array}{l}\mathrm{K}_{2} \mathbf{O} \\
(\%)\end{array}$ & $\begin{array}{l}\mathrm{Na}_{2} \mathbf{O} \\
(\%)\end{array}$ \\
\hline Gümüşhane & 18.14 & 54.43 & 2.36 & 4.17 & 14.43 & 5.04 & 0.03 & 0.55 & 0.11 \\
\hline Akçakale & 1.38 & 90.54 & 2.41 & 1.88 & 0.66 & 0.09 & 0.00 & 0.42 & 0.10 \\
\hline Besyo & 10.09 & 54.83 & 0.55 & 0.70 & 14.32 & 7.01 & 0.01 & 0.05 & 0.00 \\
\hline Kireçtaş1 (Agrega) & 43.67 & 3.64 & 1.40 & 0.41 & 30.16 & 18.19 & 0.00 & 0.39 & 0.00 \\
\hline
\end{tabular}

Tablo 3. Hızlandırılmış harç çubuğu deneyinde kullanılan agrega ve çörtlerin karışım miktarları

\begin{tabular}{|c|c|c|c|c|c|c|c|c|}
\hline \multirow{3}{*}{ Malzeme Türü } & \multicolumn{5}{|l|}{ Elek Serisi } & \multirow{3}{*}{$\mathrm{S} / \mathrm{Ç}^{*}$} & \multirow{3}{*}{$\begin{array}{l}\text { Su } \\
(\mathbf{m l})\end{array}$} & \multirow{3}{*}{$\begin{array}{l}\text { Çimento } \\
\text { (g) }\end{array}$} \\
\hline & $\begin{array}{l}\text { No:4 } \\
(4.75-2.36 \\
\text { mm) }\end{array}$ & $\begin{array}{l}\text { No:8 } \\
(2.36-1.18 \\
\text { mm) }\end{array}$ & $\begin{array}{l}\text { No:16 } \\
(1.18 \mathrm{~mm}- \\
600 \mu \mathrm{m})\end{array}$ & $\begin{array}{l}\text { No:30 } \\
(600-300 \\
\mu \mathrm{m})\end{array}$ & $\begin{array}{l}\text { No:50 } \\
(300-150 \\
\mu \mathrm{m})\end{array}$ & & & \\
\hline & $\% 10$ & $\% 25$ & $\% 25$ & $\% 25$ & $\% 15$ & & & \\
\hline Doğal agrega & $99 \mathrm{~g}$ & $247.5 \mathrm{~g}$ & $247.5 \mathrm{~g}$ & $247.5 \mathrm{~g}$ & $148.5 \mathrm{~g}$ & 0.47 & 206.8 & 440 \\
\hline Çörtler & $99 \mathrm{~g}$ & $247.5 \mathrm{~g}$ & $247.5 \mathrm{~g}$ & $247.5 \mathrm{~g}$ & $148.5 \mathrm{~g}$ & 0.47 & 206.8 & 440 \\
\hline
\end{tabular}

$* \mathrm{~S} / \mathrm{C}, \mathrm{su} /$ çimento oranı olarak ifade edilmiştir.

\subsection{Hızlandırılmış Harç Çubuğu Deneyi}

Gümüşhane ilinin 3 farklı bölgesinden alınan çörtler (Akçakale (A), Gümüşhane (G) ve Besyo (B)), Gümüşhane üniversitesinde yer alan beton laboratuvarına getirilmiştir. 3 farklı bölgeden elde edilen çörtler, ilk önce çeneli kırıcı vasıtasıyla boyut kü̧̈ültme işlemine tabi tutularak $5 \mathrm{~mm}$ altına düşürülmüştür. ASTM C 1260 standardında belirtilen ve her bir elek aralıkları için belirlenen miktarda çört agregası hazırlanmıştır (Tablo 3). Daha sonra Tablo 3'te verilen elek serilerine ve verilen miktarlara göre çört içermeyen referans numuneleri ve 3 farklı bölgeden alınan çörtlerden oluşan beton numuneleri ASTM C 1260 hızlandırılmış harç çubuğu standardına göre hazırlanmıştır. $3,7,14$ ve 28 gün kür süreleri için 3 adet hızlandırılmış harç çubuğu numunesi üretilmiştir. Hazırlanan harç çubukları saf su içerisine yerleştirilerek $80 \pm 2.0^{\circ} \mathrm{C}$ sabit isıdaki etüvde 24 saat bekletildikten sonra numunelerin ilk boy değerleri ölçülmüştür. $900 \mathrm{ml}$ saf suya, $40 \mathrm{~g}$ sodyum hidroksit eklenerek $\mathrm{NaOH}$ çözeltisi hazırlanmıştır ve bu çözelti ASR kabini içerisine konulmuştur. Sonrasında hazırlanan numuneler, çözeltiyle dolu kabin içerisine yerleştirilmiştir. Bu kabinin sıcaklığı standart gereği $80{ }^{\circ} \mathrm{C}$ 'de sabit 1sıda tutulmuş ve belirlenen kür süresine kadar harç numuneleri bu kabin içerisinde bekletilmiştir. Her bir bölgenin çört karışımlarına ait harç numunelerinin 3, 7, 14 ve 28 gün sonundaki ASR boy değişim ölçümleri gerçekleştirilmiştir. Şekil 2'de hızlandırılmış harç çubuğu deneyi aşamaları gösterilmiştir. Birim boy değişim yüzdelerini belirlemede Eşitlik 2 kullanılmıştır:

$\% L=\left(\frac{\Delta \mathrm{L}}{\mathrm{L}}\right) \times 100$

Eşitlikte;

$\% \mathrm{~L}=$ Boy değişim yüzdesi,

$\Delta \mathrm{L}=$ Örneğin boy değişimi $(\mathrm{mm})$,

$\mathrm{L}=$ Örneğin ilk uzunluğunu (mm) göstermektedir.

ASTM C 1260 hızlandırılmış harç çubuğu standardına göre harç numunelerinin 14 gün bekletildikten sonra limit değeri $\leq \% 0.10$ ise reaktif olmadığı, \% $0.10-\% 0.20$ arasında ise şüpheli, $\geq \% 0.20$ ise reaktivite potansiyeli olduğu belirtilmektedir (ASTM C 1260, 2014). 


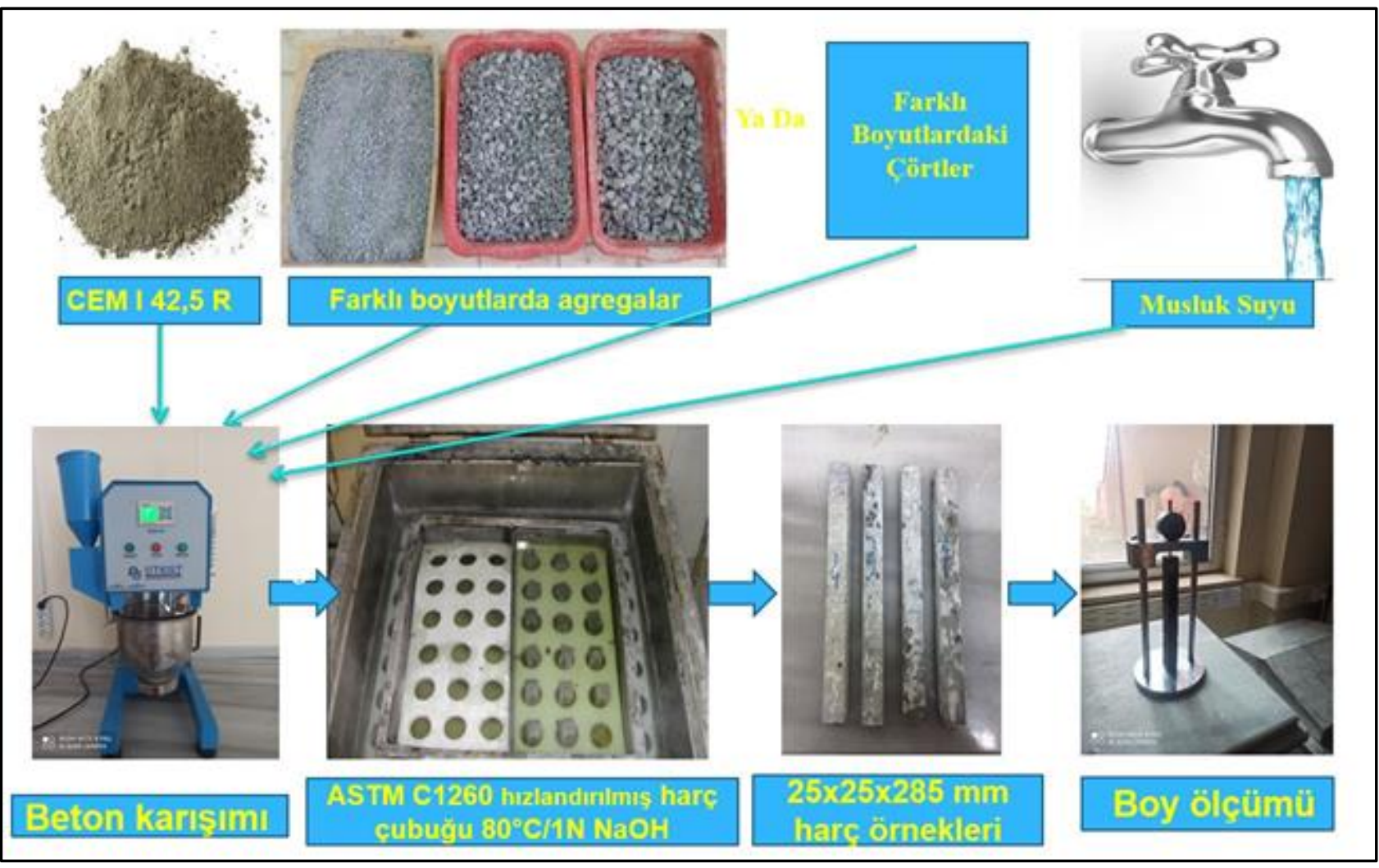

Şekil 2. Hızlandırılmış harç çubuğu deney aşamaları

\section{Bulgular ve tartışma}

Referans (R) beton harc1, Akçakale (A), Gümüşhane $(G)$ ve Besyo (B) çörtlerini içeren beton harç karışımlarının 3, 7, 14 ve 28 gün sonundaki ASR sonuçları Şekil 3-Şekil 6'da verilmiştir.
Şekil 3’te görüldüğü üzere; referans numunesinin kür süresine bağlı olarak boy değişiminin zamanla arttığ1 görülmektedir. 3. gün ASR ölçümünden 7 . gün ölçümüne 2.5 kat, 7. günden 14. güne 1.1 kat, 14. günden 28. güne ise 1.08 kat artış gerçekleşmiştir.

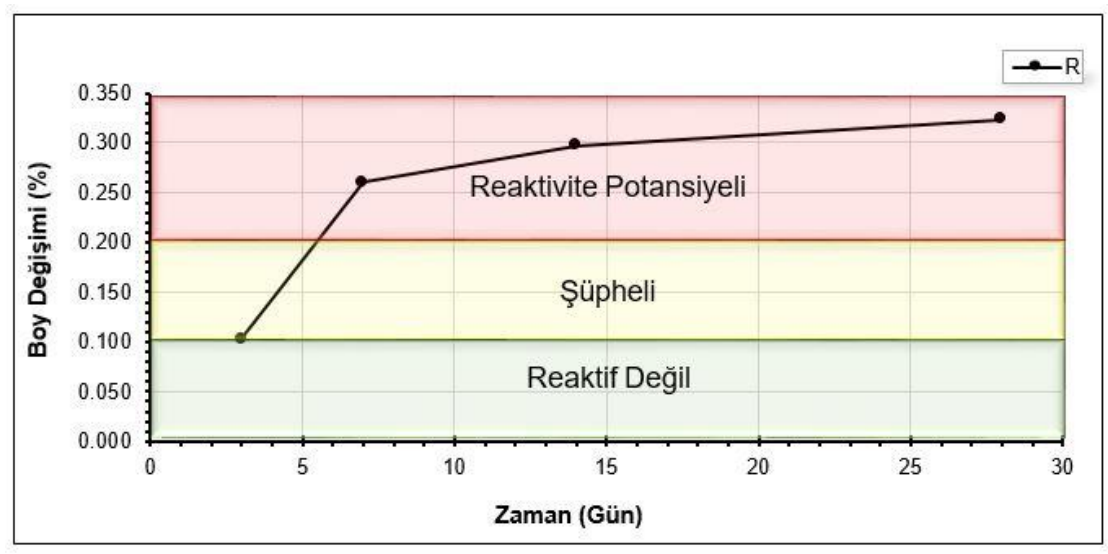

Şekil 3. Referans beton numunesi ASR sonuçları

Akçakale (A) çört numunesi ASR sonuçlarında da kür süresi bağlı olarak boy değişim değerlerinde bir artış söz konusudur. 3. gün ASR ölçümünden 7. gün ölçümüne $1.26 \mathrm{~kat}$, 7. günden 14 . güne $1.1 \mathrm{~kat}$, 14. günden 28 . güne ise 1.2 kat artış gerçekleşmiştir. Referans numunesine göre A olarak adlandırılan çörtün ASR geliştirmesi açısından etkisinin fazla olduğu görülmektedir (Şekil 4). 


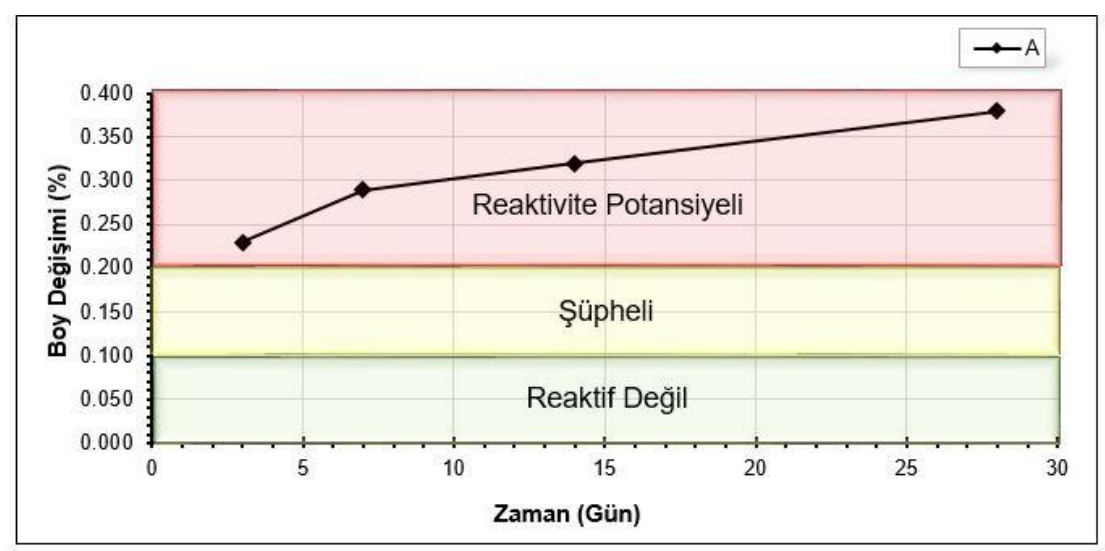

Şekil 4. Akçakale çört numunesi ASR sonuçları

Şekil 5'te görüldüğü üzere; Gümüşhane $(\mathrm{G})$ çört numunesinde de diğer numunelerde olduğu gibi ASR sonucu kür süresine bağlı olarak ASR boy değişim değerlerinde artış meydana gelmiş̧ir. 3. gün ASR ölçümünden 7. gün ölçümüne 2.21 kat, 7. günden 14. güne $1.11 \mathrm{~kat}, 14$. günden 28. güne ise 1.05 kat artış gerçekleşmiştir. Referans numunesine göre G olarak adlandırılan çörtün ASR etkisini artırdığı görülmektedir.

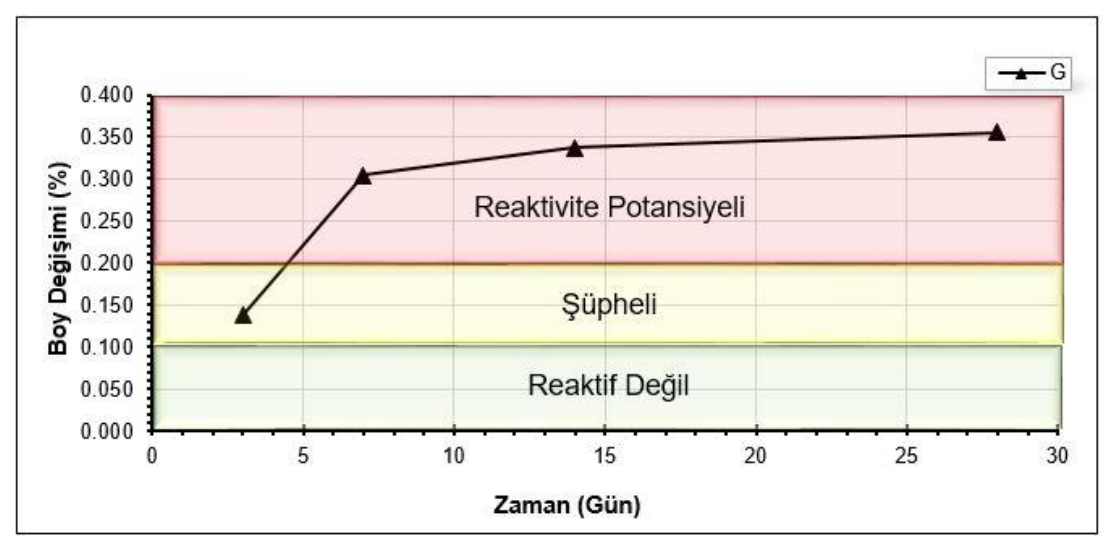

Şekil 5. Gümüşhane çört numunesi ASR sonuçları

Besyo (B) çört numunesinde de diğer numunelerde olduğu gibi ASR sonuçları kür süresine bağlı olarak boy değişim değerlerinde artış meydana gelmiştir. 3. gün ASR ölçümünden 7. gün ölçümüne 6.29 kat, 7. günden 14. güne 2.26 kat, 14 . günden 28. güne ise 1.09 kat artış gerçekleşmiştir. Referans numunesine göre B olarak adlandırılan çörtün de ASR oluşturma etkisini artırdığı görülmektedir (Şekil 6).

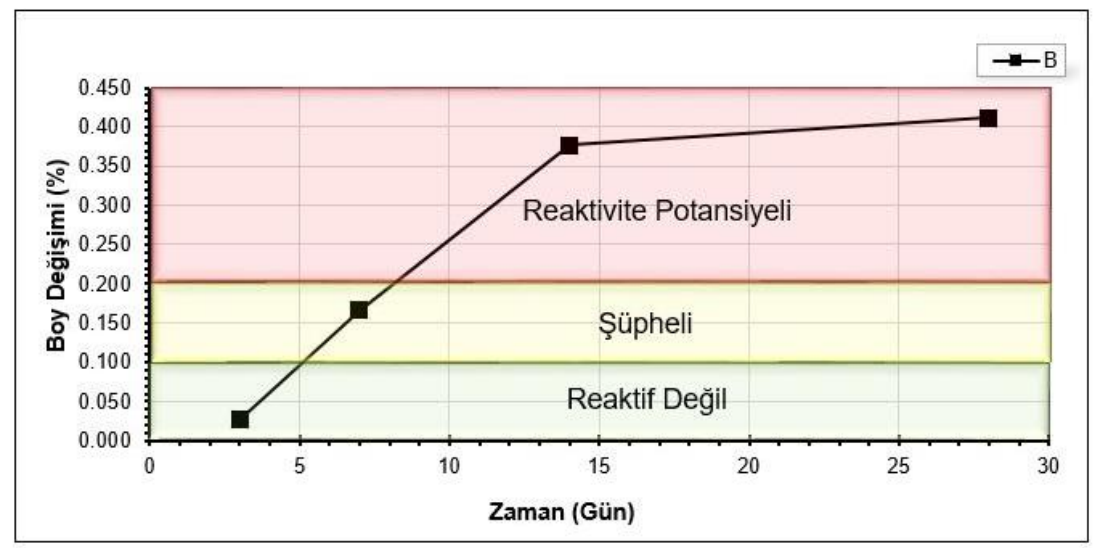

Şekil 6. Besyo çört numunesi ASR sonuçları 
Gümüşhane ilindeki 3 farklı bölgeden alınan Akçakale (A), Gümüşhane (G) ve Besyo (B) çörtlerinin beton harcında kullanımı karışımı olumsuz etkileyerek daha fazla ASR oluşmasina sebep olmuştur. Abd-Allah vd. (2018) çalışmasında belirtiği üzere; mevcut karbonat ve çört agregalarının kimyasal bileşimleri, üretilen betonda ASR reaksiyonlarının meydana gelmesine ortam hazırlamaktadır. ASR, beton gözeneklerindeki alkaliler $\left(\mathrm{Na}^{+}, \mathrm{K}^{+}\right)$arasında oluşmaktadır ve agregalardan çözünen silika alkali-silika jel oluşturmaktadır. Böylece oluşan jel suyu emerek ve sertleşmiş betonun parçalanması için gerekli genleşme (şişme) kuvvetinin oluşmasına sebep olmuştur. Ayrıca Prezzi vd. (1997), Bektas vd., (2004), Bektas vd., (2008), Moundoungou vd., 2014 Baingam vd., (2015) çalışmalarında olduğu gibi çörtlerin bünyesinde alkali iyonlarının yer alması ASR etkisinin referans numunesine göre daha fazla olmasına yol açmıştır. Bununla birlikte; ASTM C 1260 hızlandırılmış harç çubuğu standardına göre A, G, B çörtlerinden oluşan harç numunelerinin 14 gün bekletildikten sonra limit değerlerinin $\geq \% 0.20$ üzerinde olduğu ve reaktivite potansiyeline sahip olduğu belirlenmiştir.

\section{Sonuçlar}

ASTM C 1260 hızlandırılmış harç çubuğu standardına göre Gümüşhane ilinin 3 farklı bölgesinden alınan çörtler (Akçakale, Gümüşhane ve Besyo) ve kireçtaşı agregası kullanılarak hazırlanan numuneler; $3,7,14$ ve 28 gün sonunda ASR ölçümlerine tabi tutulmuştur. Sonuç olarak;

1) Kullanılan bütün çörtlerin, referans numunesine göre daha yüksek boy değişimi değerine sahip olduğu, ASR'nu artırarak beton özelliklerini olumsuz etkilediği,

2) Kür süresine bağlı olarak boy değişim değerlerinin arttığ 1 ,

3) 14 günlük boy uzama sonuçlarının ASTM C 1260 'ta belirtilen \% 0.10 zararsiz agregalar için boy uzama limitini aştı̆̆ ve \% 0.20 değerini de aşarak reaktivite potansiyeline sahip olduğu,

4) Akçakale (A), Gümüşhane (G) ve Besyo (B) çörtlerinin tamamının 14 ve 28 günlük kür sürelerinde ASTM C 1260 standardinda belirtilen sınır değerlerini aştığından dolayı betonda kullanılmaları durumunda alkali silika reaksiyonu ile betonu olumsuz yönde etkileyecekleri anlaşılmıştır.

\section{Teşekkür}

Yazarlar olarak bu çalışmamızda bizlerden yardımlarını esirgemeyen Gümüşhane Aşkale Çimento Sanayii T.A.Ş ve çalışanlarına, Ustaoğlu Grup Hazır Beton ve çalışanlarına, Gümüşhane Üniversitesi, Jeoloji Bölümü Öğr. Gör. İbrahim AKPINAR hocamıza teşekkürü bir borç biliriz.

\section{Kaynaklar}

Abd-Allah, A. M. A., Baghdady, A. R. and Dawood, Y. H. (2018). Adequacy of carbonate aggregates as an alternative for chert aggregates in concrete manufacture. Construction and Building Materials, 181, 94-105. https://doi.org/ 10.1016/j.conbuildmat.2018.06.019.

Adiguzel, D., Bascetin, A. and Baray, S., A. (2019). Determination of Optimal Aggregate Blending to Prevent Alkali-Silica Reaction Using the Mixture Design Method. Journal of Testing and Evaluation, $\quad 47(1), \quad 20160441$. https://doi.org/10.1520/jte20160441.

ASTM C 1260-14 (2014). Standard test method for potential alkali reactivity of aggregates (mortarbar method), ASTM International, West Conshohocken, PA, 2014, www.astm.org.

Baingam, L., Nawa, T., Iwatsuki, E. and Awamura, T. (2015). ASR formation of reactive chert in conducting model experiments at highly alkaline and temperature conditions. Construction and Building Materials, 95, 820-831. https://doi.org/10.1016/j.conbuildmat.2015.07.1 79.

Baradan, B., (2004). Yapı malzemesi II, Dokuz Eylül Üniversitesi, Mühendislik Fakültesi Yayınları, No:207, ss:222, İzmir.

Bektas, F., Topal, T., Goncuoglu, M. C. and Turanli, L. (2008). Evaluation of the alkali reactivity of cherts from Turkey. Construction and Building Materials, 22(6), 1183-1190. https://doi.org/10.1016/j.conbuildmat.2007.02.0 02.

Bektas, F., Turanli, L., Topal, T. and Goncuoglu, M., C. (2004). Alkali reactivity of mortars containing chert and incorporating moderate-calcium fly ash. Cement and Concrete Research, 34(12), 2209-2214.

https://doi.org/10.1016/j.cemconres.2004.02.00 7.

Brantley, S., L., Kubicki, J., D. and White, A., F. (2008). Kinetics of water-rock interaction, Springer, New York, 2008. 
Charpin, L. and Ehrlacher, A. (2012). A computational linear elastic fracture mechanics-based model for alkali-silica reaction. Cement and Concrete Research, 42(4), 613-625. https://doi.org/10.1016/j.cemconres.2012.01.00 4.

Çelik, M. Y. and Şahbaz, A. (2017). Ilıca (Kütahya) Bazaltının Beton Agregası Olarak Kullanılabilirliğinin Araştırılması. Journal of Polytechnic, https://doi.org/10.2339/politeknik.369061

Çörtler (2020, Ağustos 4), Silisli sedimanter kayaçlar (Çörtler) ve demirli sedimanter kayaçlar, Türkçe jeoloji bilgi sayfasi, https://www.jeolojitr.com/2011/09/silislisedimanter-kayaclarcortler-ve_27.html, (04.08.2020)

Demir, İ., (2010). Alkali-silika reaksiyonu etkisine maruz aynioranda silis dumani ve uçucu kül içerenharçlarin mekanik özellikleri. Gazi Üniviversitesi, Mühendislik Mimarlık Fakültesi Dergisi, 25(4), 749-758.

Demir, İ. and Arslan, M. (2013). The mechanical and microstructural properties of $\mathrm{Li} 2 \mathrm{SO} 4, \mathrm{LiNO} 3$, $\mathrm{Li} 2 \mathrm{CO} 3$ and $\mathrm{LiBr}$ added mortars exposed to alkali-silica reaction. Construction and Building Materials, 42, 64-77. https://doi.org/10.1016/j.conbuildmat.2012.12.0 59

Eker, C. S., Sipahi, F. and Kaygusuz, A. (2012). Trace and rare earth elements as indicators of provenance and depositional environments of Lias cherts in Gumushane, NE Turkey. Geochemistry, 72(2), 167-177. https://doi.org/10.1016/j.chemer.2011.11.004.

Folk, R.L., (1980). Petrology of sedimentary rocks. Hemphill, Austin, TX, 79.

Gao, X. X., Multon, S., Cyr, M. and Sellier, A. (2013). Alkali-silica reaction (ASR) expansion: Pessimum effect versus scale effect. Cement and Concrete Research, 44, 25-33. https://doi.org/10.1016/j.cemconres.2012.10.01 5 .

Gogte BS. (1973). An evaluation of some common Indian rocks with special reference to alkali aggregate reactions. Enginering Geology, 7, 135-54.

Gökçe, H. S., Şimşek, O. and Korkmaz, S. (2013). Reduction of alkali-silica reaction expansion of mortars by utilisation of pozzolans. Magazine of Concrete Research, 65(7), 441-447. https://doi.org/10.1680/macr.12.00118.

Gökçe, H. S., Üzüm, O., Hosseinnezhad, H., Hatungimana, D. and Ramyar, K. (2019).
Optimising high lime fly ash content by means of silica fume incorporation to control alkali-silica reaction and drying shrinkage of mortars. Journal of https://doi.org/10.2339/politeknik.444036. Polytechnic.

Iwatsuki, E. and Morino, K. (2008). Characteristics of alkali silica reaction of siliceous sedimentary rocks, Journal of the Society of Materials Science, $57 \quad$ (10), $\quad 967-972$. https://doi.org/10.2472/jsms.57.967

Jones, TN., (1989). Mechanism of reactions involving British chert and flint aggregates. In: Okada K, Nishibayashi S, Kawamura M, editors. Proceedings of the eighth international conference on alkali-aggregate reaction, Japan, Kyoto,p. 135-40.

Karakurt, C. and Topçu, İ. B. (2011). Effect of blended cements produced with natural zeolite and industrial by-products on alkali-silica reaction and sulfate resistance of concrete. Construction and Building Materials, 25(4), 1789-1795. https://doi.org/10.1016/j.conbuildmat.2010.11.0 87.

Larbi, J.A. and Visser, J.H.M. (2002). A study of the ASR of an aggregate with high chert content by means of ultra accelerated mortar bar test and pore fluid analysis. Heron, 47(2):141-59.

Lindgård, J., Andiç-Çakır, Ö., Fernandes, I., Rønning, T. F. and Thomas, M. D. A. (2012). Alkali-silica reactions (ASR): Literature review on parameters influencing laboratory performance testing. Cement and Concrete Research, 42(2), 223-243. https://doi.org/10.1016/j.cemconres.2011.10.00 4.

McNally C., Richardson, MG., Carr, AJ. and Strogen, P. (2004). Domain size as parameter for studying the potential alkali-silica reactivity of chert bearing aggregates. Magazine of Concrete Research, 56(4):201-9.

Morino, K., (1989). Alkali aggregate reactivity of cherty rock. In: Okada K, Nishibayashi S, Kawamura M, editors. Proceedings of the eighth international conference on alkali-aggregate reaction, Japan, Kyoto, p. 501-6.

Moundoungou, I., Bulteel, D., Garcia-Diaz, E., Thiéry, V., Dégrugilliers, P. and Hammerschlag, J. G. (2014). Reduction of ASR expansion in concretes based on reactive chert aggregates: Effect of alkali neutralisation capacity. Construction and Building Materials, 54, 147162.

https://doi.org/10.1016/j.conbuildmat.2013.12.0 36.

Murray, R.W., (1994). Chemical criteria to identify the depositional environment of chert: general 
principles and applications. Sedimentary Geology, 90, 213-232.

Nishiyama, T., Kusudai H. and Nakano, K. (1989). A few remarks on alkalireactive chert aggregates. In: Okada K, Nishibayashi S, Kawamura M, editors. Proceedings of the eighth international conference on alkali-aggregate reaction, Japan, Kyoto, p. 543-8.

Prezzi, M., Monteiro, P.J.M. and Sposito, G. (1997). The alkali -silica reaction: Part I. Use of the double-layer theory to explain the behavior of reaction-product gels, ACI Materials Journal 94(1) 10-17.

Rajabipour, F., Giannini, E., Dunant, C., Ideker, J. H. and Thomas, M. D. A. (2015). Alkali-silica reaction: Current understanding of the reaction mechanisms and the knowledge gaps. Cement and Concrete Research, 76, 130-146. https://doi.org/10.1016/j.cemconres.2015.05.02 4.

Richardson, M., (2005). Minimising the risk of deleterious alkali-silica reaction in Irish concrete practice. Construction and Building Materials, 19(9): 654-60.
Stanton, T., (1940). Expansion of concrete through reaction between cement and aggregate, Proceedings of the American Society of Civil Engineers, 66(10), 1781-1811.

Strogen, P., (1993). Studies of chert in fine and coarse aggregates in Ireland. Concrete, 27(2):26-9.

Swamy R., N., (1992), The Alkali- Silica reaction in concrete, Blackie and Son, Glasgow, pp. 128, 234,273 .

Wakizaka, W., (2000). Alkali-silica reactivity of Japanese rocks. Engineering Geology,56(1-2), 211-21.

Williams, H., Turner, FJ. And Gilbert, CH. (1982). Petrography. New York: WH Freeman and Company; 1982.

Yurtdas, I., Chen, D., Hu, D. W. And Shao, J. F. (2013). Influence of alkali silica reaction (ASR) on mechanical properties of mortar. Construction and Building Materials, 47, 165-174. https://doi.org/10.1016/j.conbuildmat.2013.04.0 46. 